\title{
The Colour of Gold-Silver-Copper Alloys
}

\author{
QUANTITATIVE MAPPING OF THE TERNARY DIAGRAM \\ Randall M. German*, Matthew M. Guzowski and David C. Wright \\ The J.M. Ney Co., Bloomfield, CT., U.S.A. \\ ${ }^{*}$ Now with the School of Engineering, Rensselaer Polytechnic Institute, Troy, N.Y., U.S.A.
}

\begin{abstract}
The first colour diagram of the gold-silver-copper system was published over 30 years ago by Josef Leuser. This was based on visual, and therefore subjective, colour assessment. Renewed interest in the colour characteristics of gold alloys, as well as the development of improved instrumentation for their measurement, have stimulated recent research on the subject. This has now progressed to the point where objective, quantitative information on the relationship between alloy colour and composition is available.
\end{abstract}

Roberts and Clarke (1) recently published colorimetric data for binary and ternary alloys in the gold-silver-copper system. At about the same time, we also presented colour measurements for a smaller range of alloy compositions $(2,3)$. The objective of the latter work and of that reported here has been to establish the effects of composition on alloy colour, and then to use colour difference measurements as a basis for quantifying the tarnish resistance of goldsilver-copper alloys.

Where colour difference measurements are intended, it is highly desirable to use a so-called uniform colour space in order to facilitate visualizing the degree of difference, irrespective of the precise colour. A uniform colour space has the property that a perceived difference between colours is quantitatively the same in all its areas. The CIELAB system of colour representation satisfies this unique requirement and was therefore selected for this investigation. In what follows, our own results are combined with those of Roberts and Clarke, after conversion of the latter into the CIELAB system, and a compilation of the colour characteristics of gold-silver-copper alloys is presented in the form of topological projections on the ternary diagram.

\section{Experimental Details}

The alloys used for this investigation were prepared from 99.9 per cent pure metals. Paddle-shaped samples, $10 \times 10 \times 1 \mathrm{~mm}$ in size, were cast from previously alloyed buttons. These samples were then polished by standard metallographic techniques.

The colour measurements were performed on a Diano Corporation Match-Scan DTM 1045 com- puterized spectrophotometer. The light source was simulated daylight having a $6500 \mathrm{~K}$ black-body temperature. (Roberts and Clarke used a slightly different source, the CIE standard illuminant $\mathrm{C}$ with a black-body temperature of $6740 \mathrm{~K}$ ).

\section{The CIELAB System}

The CIELAB uniform colour scale relies on the same tristimulus coloured light mixing approach as the 1931 CIE chromaticity chart described in this journal by Roberts and Clarke. It is an orthogonal, three-dimensional space in which colour is defined by three co-ordinates, namely lightness $L^{\star}$, red-green $a^{\star}$ and yellow-blue $b^{\star}$ (Figure 1). The $L^{\star}$ values may

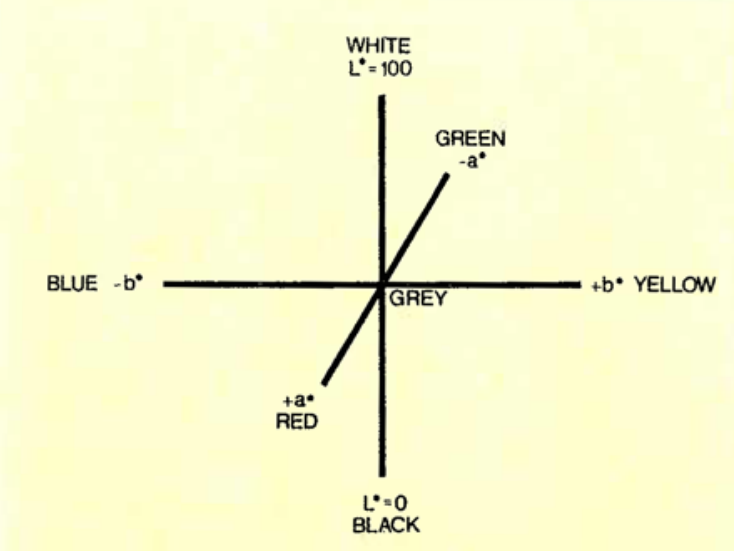

Fig. 1 The three-dimensional CIELAB system of orthogonal colour co-ordinates. The colour of an object is defined by a white-black component $L^{*}$, a red-green component $a^{*}$ and $a$ yellow-blue component $b^{*}$ 

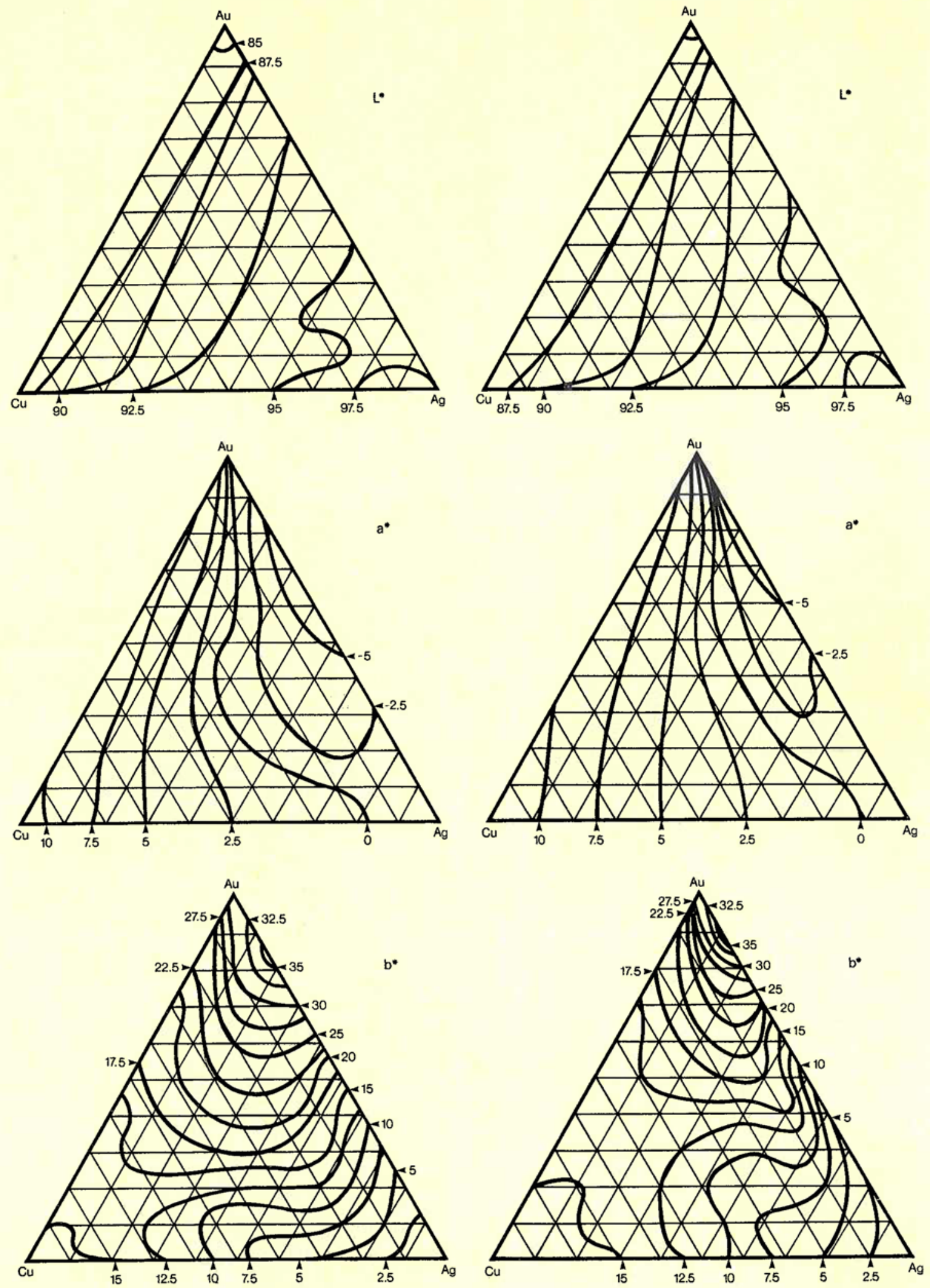

Fig. 2 Gold-silver-copper ternary diagrams showing the effect of atomic alloy composition on the three CIELAB colour co-ordinates $\mathrm{L}^{*}, \mathrm{a}^{*}$ and $\mathrm{b}^{*}$. The spacing between contours is 2.5 units on each of the colour scales

Fig. 3 Gold-silver-copper ternary diagrams showing the effect of alloy composition by weight on the three CIELAB co-ordinates $L^{*}, a^{*}$ and $b^{*}$. The spacing between contours is 2.5 units on each of the scales 
range from 0 (black) to 100 (white), with intermediate values representing various degrees of luminance. Positive $a^{\star}$ values correspond to red colours, with higher positive $a^{\star}$ values representing more intense (saturated) red; negative $a^{\star}$ values correspond to green colours. Positive values of the third co-ordinate $b^{\star}$ are associated with yellow dominance and negative values with blue dominance.

There are several advantages to using the CIELAB system. First, colour description is fully quantitative and is based on the concept of complementary colours. Secondly, the units on all three orthogonal scales are representative of approximately equal increments of colour difference, thereby making this a uniform colour space. Thus, there is a meaningful relationship between the CIELAB representation and perception of colour differences by the buman eye. This correlation between the values of $L^{\star}, a^{\star}$ and $b^{\star}$, and visual colour difference assessments made the use of the CIELAB system particularly appropriate for the present work.

The values of $L^{\star}, a^{\star}$ and $b^{\star}$ for a given sample are obtained as direct read-outs from a computerized spectrophotometer such as that used for this study. The colour difference between two specimens may be easily calculated as the vectorial colour distance between them and is therefore expressed as a single parameter, $\Delta \mathrm{E}^{\star}$. The total difference between two samples of colour co-ordinates $L_{1}^{\star}, a_{1}^{\star}$, and $b_{1}^{\star}$, and $\mathrm{L}_{2}^{\star}, \mathrm{a}_{2}^{\star}$, and $\mathrm{b}_{2}^{\star}$, respectively, is given as:

$$
\Delta \mathrm{E}^{\star}=\left[\left(\mathrm{L}_{1}^{\star}-\mathrm{L}_{2}^{\star}\right)^{2}+\left(\mathrm{a}_{1}^{\star}-\mathrm{a}_{2}^{\star}\right)^{2}+\left(\mathrm{b}_{1}^{\star}-\mathrm{b}_{2}^{\star}\right)^{2}\right]^{1 / 2}
$$

and $\Delta \mathrm{E}^{\star}$ is a truly quantitative measure of colour difference. This feature is of great use in quality control functions, since only the $\Delta \mathrm{E}^{\star}$ tolerance, rather than a range of permissible values for each of $L^{\star}, a^{\star}$ and $b^{\star}$, need be specified. With respect to dental and jewellery alloys, $\Delta \mathrm{E}^{\star}$ may be of particular importance, not only in matching the colour of components made of different alloys and/or by different processes, but also in quantifying alloy colour stability in tarnishing environments $(2,3)$. A value of 1 for $\Delta E^{\star}$ is normally just discernible by the average human eye.

The 1931 CIE colour co-ordinates published by Roberts and Clarke can be converted easily into the CIELAB system. These authors tabulated the $\mathrm{Y}, \mathrm{x}$ and $y$ values derived from measurements of the tristimulus values $\mathrm{X}, \mathrm{Y}$ and $\mathrm{Z}$. These variables are inter-related as follows:

$$
x=\frac{X}{X+Y+Z}, \quad y=\frac{Y}{X+Y+Z} \quad \text { and } z=1-x-y
$$

The original $\mathrm{X}, \mathrm{Y}$ and $\mathrm{Z}$ values can therefore be calculated from the published $\mathrm{Y}, \mathrm{x}$ and $\mathrm{y}$ values.
Knowing the light source stimulus values $\mathrm{X}_{\mathrm{O}}, \mathrm{Y}_{\mathrm{O}}$ and $Z_{O}$ allows calculation of $L^{\star}, a^{\star}$ and $b^{\star}$ as follows:

$$
\begin{aligned}
& \mathrm{L}^{\star}=116\left(\mathrm{Y} / \mathrm{Y}_{\mathrm{O}}\right)^{1 / 3}-16 \\
& \mathrm{a}^{\star}=500\left[\left(\mathrm{X} / \mathrm{X}_{\mathrm{O}}\right)^{1 / 3}-\left(\mathrm{Y} / \mathrm{Y}_{\mathrm{O}}\right)^{1 / 3}\right] \\
& \mathrm{b}^{\star}=200\left[\left(\mathrm{Y} / \mathrm{Y}_{\mathrm{O}}\right)^{1 / 3}-\left(\mathrm{Z} / \mathrm{Z}_{\mathrm{O}}\right)^{1 / 3}\right]
\end{aligned}
$$

For the light source which was used by Roberts and Clarke, $\mathrm{X}_{\mathrm{O}}=98.9795, \mathrm{Y}_{\mathrm{O}}=100.0000$ and $\mathrm{Z}_{\mathrm{O}}=118.2246$ (4).

Our colour measurements showed one standard deviation errors of \pm 0.8 for $L^{\star}, \pm 0.2$ for $a^{\star}$ and \pm 0.5 for $b^{\star}$. In general, where alloy compositions that had been investigated by Roberts and Clarke were re-studied in the present work, the results agreed within these ranges of error. For example, on the 30 gold $/ 30$ silver $/ 40$ copper weight per cent alloy, our results were $L^{\star}=90.3, a^{\star}=4.6$ and $b^{\star}=13.0$, while the values transformed from the 1931 CIE coordinates were $90.8,4.2$ and 12.8 respectively, giving a value of 0.67 for $\Delta \mathrm{E}^{\star}$.

\section{Results}

The CIELAB co-ordinates $L^{\star}, a^{\star}$ and $b^{\star}$ measured in the authors' laboratory and those converted from Roberts and Clarke's data have been plotted against alloy composition. The results are shown superimposed on the gold-silver-copper ternary diagram in Figures 2 and 3. In Figure 2, the three variables are plotted as constant value topological projections with a uniform spacing of 2.5 units. The composition scale is on an atomic per cent basis. Figure 3 shows the same data with the composition on a weight per cent basis. In this latter case, the widely differing atomic masses of gold, silver and copper result in a distortion of the colour profiles towards the gold corner. This novel presentation of colour gradations in gold-silvercopper ternary alloys is more precise than Leuser's well known qualitative diagram (5) which is helpful in defining colour regions, but is vague, subjective and conducive to varying interpretations.

It is interesting to note that binary alloys of approximate composition 85 gold/15 silver atomic per cent have the most intense yellow colours. In general, gold has a strong yellowing and copper a strong reddening effect. Silver contributes markedly to the alloy lightness ( $\mathrm{L}^{\star}$ increases when silver is added) and causes greening in low copper alloys. An important result of additional work performed for this study is that sample colour appears to be solely dependent on alloy composition - microstructure and heat treatment can be discounted as variables. This holds true even for complex alloys. For example, an alloy of composition 20 gold $/ 30$ silver $/ 48$ copper $/ 2$ platinum atomic per cent, having a Brinell hardness of 132 in the as-cast condition and a hardness of 190 after heat 
treatment for 10 minutes at $370^{\circ} \mathrm{C}$, exhibits identical colour co-ordinates, namely $L^{\star}=86, a^{\star}=3$ and $\mathrm{b}^{\star}=12$, in both conditions.

\section{Conclusions}

The use of a computerized spectrophotometer to measure alloy colour is a major advance in quantifying this important design criterion. The emphasis on gold-silver-copper alloys for initial work corresponds to the predominance of jewellery and dental alloys based on this system. A quantitative colour map, based on a uniform colour space, is now available, which reveals that composition, the controlling factor, and alloy colour are related in a complex manner. The concepts exposed above have been used in studies of alloys with more than three constituents and, in particular, have been applied successfully in the formulation of new dental gold alloys meeting specific criteria. With the current interest in dental alloys with lowered noble metal contents, application of these same experimental methods to quantifying colour stability (tarnish resistance) is proving a valuable tool for alloy development.

\section{References}

1 E. F. I.Roberts and K. M.Clarke, Gold Bull., 1979, 12,(1), 9-19

2 D. C. Wright and R. M. German, in 'Proc. Dent. Mater. Group, Int. Assoc. Dent. Res.', New Orleans, LA., March 1979, available from Dr. D. Eick, School of Dentistry, Oral Roberts University, Tulsa, OK., U.S.A.

3 M. M. Guzowski, D. C. Wright and R. M. German, presentation to the Third International Precious Metals Conference, Chicago, IL., U.S.A., May 1979

4 P. S. Hunter, Ind. Res. Dev., 1979 (August), 67-72

5 J. Leuser, Metall, 1949, 3, ]05-110,128

Leuser's diagram was reproduced in:

'Gold: Recovery, Properties and Applications', edited by E. M. Wise, D. Van Nostrand Co., Inc., Princeton, NJ., 1964 p. 262

W. S. Rapson and T. Groenewald, 'Gold Usage', Academic Press, London, 1978, p. 37

A. S. McDonald and G. Sistare, Gold Bull., 1978, 11, (2), 68

\section{Cloth of Gold and its History}

\section{The Gold and Silver Wyre-Drawers}

BY ELIZABeth GLover, Phillimore, Chichester, England, 1979, 91 pages, $£ 17.50$

There are many records of the extravagant display of finery that characterized the Field of the Cloth of Gold, the name given to the month-long meeting of Henry VIII and Francis I, the French king, near Calais in 1520, and most visitors to Britain must at some time have had an opportunity to admire the gorgeous uniforms of the State Trumpeters of the Household Cavalry, the Royal Heralds or the Drum Majors of the Brigade of Guards. Much of this splendour comes of course from the embroidery worked in gold wire. If rather less resplendent, the uniforms of the higher echelons of the world's armies, navies and air forces all display at least something of the same regard for gold braid, while ecclesiasical vestments have for many centuries been richly decorated by the same means.

The manufacture of gold wire - or more strictly goldclad silver wire - for use in textiles and embroidery is an ancient craft; it is mentioned, for example, in the Book of Exodus, where the making of the ephod for the tabernacle is described:

'The gold was beaten into thin plates, cut and twisted into braid to be worked in by a seamstress with the violet, purple and scarlet yarn, and fine linen.'

In fact, the very early technique did consist of covering skins or vellum with gold foil, cutting into very thin strips and winding this closely round a thread of silk or hemp. By the fifteenth century, however; wire drawing had been practised for some time, while flattening of the wire to enable it to be wound round silk to make thread was introduced in the mid-sixteenth century. Well before this time English embroidery with a plentiful use of gold and silver wire was highly regarded throughout Europe and in fact became known as Opus Anglicanum. This was essentially a Londonbased cottage industry and the present volume gives a most fascinating history of it and of the craft guild that was formed to control the trade, to maintain standards and to establish a seven-year period of apprenticeship.

The author is a skilled and experienced archivist, and she has had full access to the records and minute books of the Worshipful Company of Gold and Silver Wyre-Drawers, one of the smaller City Livery Companies of London and one that still maintains connections with the trade. Its first full charter was granted in 1693, although a rather unsatisfactory charter of sorts had been obtained from Charles I in 1623. One John Garill, a well known gold and silver wire-drawer, had claimed in 1662 to have developed a new process 'for casting and preparing gold and silver ingots for making wire and lace' and was granted a patent for his invention in the following year. This of course aroused the anger of his competitors, some thirty or so master craftsmen who controlled large numbers of out-workers, and after lengthy and expensive negotiations a proper charter was granted.

The book gives details of all the known gold and silver wire-drawers in London in the early period and goes on to describe the trade and its markets in later centuries. The Industrial Revolution brought about great changes in the nineteenth century, and part of the London trade was lost to Lancashire, where the weaving of gold thread into cotton textiles had the obvious advantage that it withstood the bleaching process, and where powered machinery was adopted. New outlets were found and trade expanded throughout the world, but today, unfortunately, only one firm remains - in Preston in Lancashire. However, as Mrs. Glover concludes 'it is enough to say that the industry survives and that what it does is well done'.

This account of a minor but highly decorative use of gold - including a technical chapter on modern production practice - gives a fascinating picture of progress in an ancient craft over more than five hundred years. 